\title{
Roles of surface chemistry and structural defects of activated carbons in the oxidative desulfurization of benzothiophenes
}

\author{
Michael T. Timko ${ }^{\mathrm{a}, *}$, Jin An Wang ${ }^{\mathrm{a}, \mathrm{b}}$, James Burgess, ${ }^{\mathrm{c}}$ Peter Kracke, ${ }^{\mathrm{d}}$ Lino Gonzalez, ${ }^{\mathrm{d}}$ \\ Cherno Jaye, ${ }^{\mathrm{e}}$ Daniel A. Fischer ${ }^{\mathrm{e}}$ \\ ${ }^{a}$ Department of Chemical Engineering \\ Worcester Polytechnic Institute, 100 Institute Road \\ Worcester, MA 01609-2280, USA \\ ${ }^{b}$ ESIQIE \\ Instituto Politécnico Nacional \\ Av. Politecnico s/n, Col. Zacatenco, 07738 México D. F., Mexico \\ ${ }^{\mathrm{c}}$ Bruker Optics, Inc. \\ 19 Fortune Dr. \\ Billerica MA 01821 \\ dAerodyne Research Inc. \\ Center for Aero-Thermodynamics \\ Billerica, MA 01821 \\ ${ }^{\mathrm{e}}$ NIST \\ Materials Measurement Lab \\ Gaithersburg, MD 20899 USA
}

\begin{abstract}
A range of different activated carbons was characterized and evaluated for promotion of the oxidative desulfurization (ODS) of JP-8 fuel using $\mathrm{H}_{2} \mathrm{O}_{2}$ oxidant and acetic acid. Wood-based carbons activated by acid treatment showed much higher effectiveness than all other carbon types, regardless of source or activation method. Under identical test conditions designed to differentiate material performance, the most effective carbon material yielded $69 \%$ oxidation of 2,3-dimethylbenzothiophene (2,3-DMBT) whereas the ineffective materials scarcely out-performed the control (10\% oxidation). To understand the characteristics most associated with reaction promotion, the textural, chemical, and defect features of the carbon materials were examined using a battery of
\end{abstract}


techniques. The effective promoters all shared in common high surface areas and high pore volumes; however, surface area and pore volume alone could not explain the observed trends in performance. Investigating surface chemistry, presence of strong acid sites was strongly related to ODS performance. Overall, long-range order was not required for high activity, yet neither were edge defect sites. These results suggest that carbon promotes ODS by formation of percarboxylic acid species at defect sites within the carbon basal planes. Post-reaction analysis of the carbon materials provided evidence to support this explanation.

Keywords: Activated carbon; oxidative desulfurization; surface acidity; structural defects; spectroscopic characterization; jet fuel.

\section{Introduction.}

Because of increasingly stringent environment legislations, sulfur content in transportation fuels has been strictly limited to very low levels. For example, in the USA, the acceptable level of sulfur in diesel was reduced to 500 ppm in 1995 by the Clean Air Act amendments; it was then reduced to $350 \mathrm{ppm}$ in $2000 ; 50 \mathrm{ppm}$ in 2005 ; and finally $15 \mathrm{ppm}$ since 2006.[19] Similarly, in the European Union, maximum sulfur in the market diesel was reduced to 10 ppm since 2008.[10] To address these strict regulatory requirements, several technologies have been developed for deep desulfurization of oil refinery fuels, which can be generally classified[11] into hydrodesulfurization (HDS),[2, 12-14] oxidative desulfurization (ODS),[15-23] biodesulfurization [24-28], adsorption desulfurization (ADS),[6, 29-41] and extractive desulfurization using organic solvent, ionic liquids, [42, 43] 
or deep eutectic solvent mixtures.[44] Of these different technologies, ODS has proven effective at reducing sulfur concentrations in fuels to meet the new legislations.[11] Among a wide variety of materials that have been examined for ODS, carbon-based materials[18, 45-47] have attracted great attention because of their abundance, low cost, large surface area (500-2500 m²/g), satisfactory porous structure (varying from micro- to mesoporosity), and high surface concentration of oxygen functional groups.[31-33, 36, 48-51]

For activated carbon promoted ODS, the strategy is to oxidize fuel sulfur compounds to increase their polarity, and then remove them from the fuel by adsorption onto a polar sorbent.[52, 53] Thus, oxidation and adsorption may be combined into one process with the carbon playing simultaneous adsorption and catalytic roles. Even without sulfur compound oxidation, some carbon materials have shown high capacity and selectivity in the removal of dibenzothiophenes (DBTs) from petroleum fuels.[7, 31-33, 3638, 49, 51] For example, Triantafyllidis et al.[54] reported that the dibenzothiophene adsorption capacity of carbon materials could be correlated with their micro- and mesoporosity. In separate works, correlations[31, 50, 55, 56] between adsorption capacity and the chemical properties of the carbon surface have been established.

Unfortunately, most of the published papers regarding desulfurization using carbon materials are confined to model fuels with only a limited number of papers on the studies of activated carbon as a catalyst for real fuel desulfurization.[2, 18, 19] Furthermore, although the surface chemistry of carbons has been shown important for thiophenic compound adsorption[31-33, 36, 50, 57] and (separately) catalysis,[31, 58-60] the specific role of activated carbon in promoting the oxidation reaction is not yet clear. As a result, relationships between carbon characteristics and performance are unknown, making process optimization a trial-and-error process. 
In previous work, we found that carbon-promoted ODS was capable of achieving $<10$ ppm sulfur levels in JP-8 jet fuel and that a wood-based carbon was more effective than a peat-based carbon.[18] Safe concentrations of the low-cost oxidant hydrogen peroxide were used in the process, along with low concentration of formic acid. The oxidant phase is fuel immiscible,[52,61] permitting $>90 \%$ fuel recovery post-treatment even at small scale.[18]

The challenge in ODS is achieving cost competitiveness with HDS. To improve the economics of ODS, we therefore set out to understand the role of the activated carbon promoter so as to reduce its use, thereby improving process economics. In a second published work[19] we showed that, depending on the types of sulfur compounds present in the fuel, either oxidization of the benzothiophene (BT) content[62] or removal of oxidized sulfides/disulfides/thiophenes[63] could limit overall ODS performance. Given that BT oxidation can limit ODS performance, the motivation of our ongoing research was the selection of the best carbon material for oxidation of BT compounds.[19] Again, our previous work $[18,19]$ indicated that all BT compounds responded similarly to the carbonpromoted ODS treatment and that 2,3-DMBT was the most recalcitrant of the jet fuel BT compounds. Hence, we focused our attention on ODS of this compound.

We have measured the BT oxidation performance of performic acid in the presence of a range of activated carbons, representing different raw materials (peat, wood, coal), different activation protocols (steam, acid), and different vendors. The carbons were then characterized using a battery of techniques including $N_{2}$ physisorption, solid state Boehm titration, Diffuse Reflectance Infrared Fourier Transform Spectroscopy (DRIFTS), Raman microspectroscopy, and carbon k near edge X-ray absorption fine structure (C K-NEXAFS) 
spectroscopy to investigate the roles of textural, chemical, and defect features on ODS promotion effects. Based on the combined analysis results, we hypothesize a mechanism of ODS promotion by activated carbon that involves transient formation of highly active surface-bound percarboxylic acid sites.

\section{Experimental Methods}

\subsection{Carbon materials}

In this work, 12 carbon materials were examined for ODS performance. The carbon materials were donated by Meadwestvaco, Pica, and Norit (since purchased by Cabot). Table 1 lists the carbon materials, the feedstock used as the carbon source, activation method, and vendor information. The carbon materials can be classified into 3 groups: 8 samples are wood-based carbons, 2 are peat based carbons, and 2 are coal-based carbons. Activation methods include phosphoric acid, steam, ammonia, and thermal treatment. We have also tested several carbon black materials and found them to be active for ODS promotion but these results are not presented here. All carbons were used after washing with copious amounts of DI water $(10 \times$ volume $)$ and oven drying over night at $80-100{ }^{\circ} \mathrm{C}$.

\subsection{ODS promotion Tests}

All ODS promotion tests were performed in 40-mL disposable glass sample vials (obtained from Ace Glass with PTFE-lined caps) that were agitated at room temperature using a wrist-action shaker (Burrell). Up to 8 samples could be processed at a time, providing a rapid procedure to perform ODS performance tests. Table 2 provides typical conditions used for shaker tests. In previous work, $[18,19]$ we have already shown that the activated 
carbon promoted ODS technique can be effective; the ODS conditions used in the current study were selected to provide a maximum range in performance so that carbons could be differentiated more precisely. Accordingly, superior ODS performance and rates could have been achieved using similar materials simply by increasing the reaction temperature as we have previously demonstrated.[18]

JP-8 jet fuel, donated by the Air Force Research Laboratory and with a fuel sulfur content of $717 \mathrm{ppm}_{\mathrm{w}}$, was used for all tests. JP-8 contains a complex mixture of benzothiophene and sulfide/disulfide/thiophene compounds.[19, 62, 63] Following on our earlier work,[18] we tracked ODS performance by monitoring the disappearance of BT compounds. Here, we report data for disappearance of 2,3-dimethylbenzothiophene (2,3DMBT) specifically. We select this compound for reporting purposes as we previously found that all BT compounds responded similarly to the ODS treatment, with 2,3-DMBT being the most recalcitrant.[18] Accordingly, oxidation data for 2,3-DMBT are representative of BT compounds as a class.

Treated fuels were analyzed for BT and specifically 2,3-DMBT content using a gas chromatograph (GC, Agilent 6890) coupled to a mass selective detector (MS, Agilent 5975) in select-ion mode using $\mathrm{m} / \mathrm{z}=162$ and a retention time of $11 \mathrm{~min}$. As shown in the Supporting Information, the BT content of JP-8 is easily identified using this technique. The details of the GC method are: HP-5MS (Agilent column); 40:1 split ratio; $80{ }^{\circ} \mathrm{C}$ initial temperature (with a $1 \mathrm{~min}$ hold time); $5{ }^{\circ} \mathrm{C} / \mathrm{min}$ to $100{ }^{\circ} \mathrm{C} ; 10{ }^{\circ} \mathrm{C} / \mathrm{min}$ to $300{ }^{\circ} \mathrm{C} ; 25 \min$ total run time. In all cases, at least 3 repeats were performed for each carbon material and the discrepancy in 2,3-DMBT removal performance for these runs was always less than 5\% and usually less than $3 \%$. 


\subsection{Materials Characterization Methods}

Carbon samples were analyzed using $\mathrm{N}_{2}$ physisorption, Boehm titration, $\mathrm{NH}_{3}$-temperature programmed desorption ( $\mathrm{NH}_{3}$-TPD), DRIFTS, x-ray photoelectron spectroscopy (XPS), and C K-NEXAFS. Except where noted, carbon samples were rinsed with copious water until a neutral $\mathrm{pH}$ was reached, dried overnight at $80-100{ }^{\circ} \mathrm{C}$, and stored in air-tight containers before analysis.

2.3.1. $\mathbf{N}_{2}$ Physisorption. The surface areas of the samples were determined at $-196{ }^{\circ} \mathrm{C}$ on a Micromeritics ASAP 2000 apparatus, using $\mathrm{N}_{2}$ as adsorbent. Surface areas were determined using the Brunauer-Emmett-Teller (BET) model. Before the adsorption-desorption experiments, all the samples were thermally heated at $300{ }^{\circ} \mathrm{C}$ for $12 \mathrm{~h}$.

2.3.2. Raman spectroscopy. Raman spectra were recorded from 500 to $3500 \mathrm{~cm}^{-1}$ on a Bruker Senterra Raman microscope using a $532 \mathrm{~nm}$ laser line at $2 \mathrm{~mW}$ with 10 samples scans performed at room temperature. Because most of the Raman bands related to surface microstructure of carbon are present between 1000 and $2000 \mathrm{~cm}^{-1},[64-66]$ we focus our analysis on this spectral region. In all cases, peak position, integrated area and width (FWHM) of Raman bands of each spectrum were determined using the Magic Plot software, using a combination of Gaussian and Lorentzian profiles to fit the first-order region, for the graphite $\mathrm{G}$ band[64] at approximately $1590 \mathrm{~cm}^{-1}$ and the defects bands (either D or D1, D2, D3 and D4).[65]

2.3.3. Fourier transform infrared spectroscopy (FTIR). Diffuse reflectance infra-red Fourier transform spectroscopy (DRIFTS) was performed on powder samples using a Thermo-Fisher FTIR6700 with DRIFTS accessory. Spectral resolution was $2 \mathrm{~cm}^{-1}$ and all samples were purged by $\mathrm{N}_{2}$ gas for 20 minutes prior to analysis to exclude atmospheric $\mathrm{CO}_{2}$ and $\mathrm{H}_{2} \mathrm{O}$ from the sample space. 


\subsubsection{Near edge X-ray absorption fine structure (NEXAFS) spectroscopy. NEXAFS}

measurements were carried out at the NIST U7A beamline National Synchrotron Light Source (NSLS). Carbon K-NEXAFS spectra were obtained in partial electron yield (PEY) mode using a channeltron electron multiplier and entrance grid bias of $-150 \mathrm{~V}$ with the sample surface placed $54.7^{\circ}$ relative to the incident X-ray beam. Incident beam fluctuations and beamline optics absorption were eliminated by normalizing all the spectra with the drain current of a clean Au mesh located upstream of the sample, while the energy was calibrated using the $285.1 \mathrm{eV} \pi^{*}$ feature of a carbon mesh also located upstream.

2.3.5. Boehm titration. The surface oxygen functional groups on carbon samples were determined using the Boehm titration method.[54-56, 67] The densities of different oxygen functional groups were calculated on the basis of the amounts of selected bases $\left(\mathrm{NaHCO}_{3}\right.$, $\mathrm{Na}_{2} \mathrm{CO}_{3}$, and $\left.\mathrm{NaOH}\right)$ used to neutralize different acidic sites.

\subsubsection{Additional Supporting Measurements: Temperature-programmed desorption of} ammonia ( $\mathbf{N H}_{3}$-TPD) and X-Ray Photoelectron Spectroscopy (XPS). $\mathrm{NH}_{3}$-TPD and XPS analysis were performed to support the core measurements (Raman microspectroscopy, DRIFTS, Boehm titration, sorption analysis, and NEXAFS). Detailed method descriptions are provided in the Supporting Information.

\section{Results and discussion}

\subsection{ODS Activity}

The sulfur removal results obtained by tracking 2,3-DMBT disappearance are reported in Table 3. Sulfur removal percentages varied from approximately $10 \%$ to $70 \%$, depending on the carbon sources and treatment. In our prior work, $[18,19]$ we showed that the carbon-promoted ODS method could achieve $>90 \%$ sulfur removal; here, we performed 
the treatment at lower reaction temperatures $\left(25^{\circ} \mathrm{C}\right.$ compared to $\left.60{ }^{\circ} \mathrm{C}\right)$ so that statistically significant ODS results could be obtained for a large number of carbon materials and so that high performing materials could be clearly differentiated from less active ones. Control experiments performed in the absence of carbon promoter provided $10 \% 2,3$ DMBT removal; any material that provided $10 \pm 3 \%$ removal (the limits of reproducibility) therefore showed no promotion effect.

Table 3 reports data exclusively for 2,3-DMBT; we previously[18, 19] found that all BT compounds present in JP-8 responded similarly to the carbon-promoted ODS treatment. Indeed, the GC-MS technique used here can differentiate between the various BT compounds and we focus our attention exclusively on 2,3-DMBT as have previously found[18] it to be the most recalcitrant BT compound present in JP-8. Extensive tests, reported previously, confirm that the carbon-based ODS approach can reduce JP-8 sulfur content below $50 \mathrm{ppm}_{\mathrm{w}}[19]$ and even $10 \mathrm{ppm}_{\mathrm{w}} \cdot[18]$

Some conclusions can be drawn from the data in Table 3: First, wood-based carbons treated with phosphoric acid exhibit the best ODS performance of all the carbons tested. For example, using HP-120 sample, around $70 \%$ of the 2,3-DMBT present in jet fuel could be removed. Second, all other carbon types provided 2,3-DMBT removal performance scarcely better than the control. Third, acid treatment by phosphoric acid is superior to base treatment by ammonia, as evidenced by the fact that the $\mathrm{NH}_{3}$-activated wood-based carbon, Aquaguard, shows the lowest ODS performance of all the materials tested.

The observation that acid-treated wood-based carbons are effective ODS promoters is purely phenomenological; to gain more insight into the different factors that contribute to the effectiveness of carbon materials for ODS promotion, we analyzed representative 
carbons to determine their textural properties, surface oxygen content, surface acid content, and defect content. The results are summarized in the following sections.

\subsection{Textural Properties $-\mathrm{N}_{2}$ Physisorption}

Textural properties of the activated carbon materials were measured using $\mathrm{N}_{2}$ sorption. Table 3 summarizes BET surface area data, showing that most samples have surface area greater than $1000 \mathrm{~m}^{2} \mathrm{~g}^{-1}$. In general, the acid-treated, wood-based carbons have greater surface areas than the other carbon types. For instance, the highly effective HP-120 sample has the largest surface area of $2200 \mathrm{~m}^{2} \mathrm{~g}^{-1}$. Within the subset of wood based catalysts, however, a strict relationship between surface area and ODS performance was not observed. For example, Darco KBG has a lower surface area than MW 99-R-06 (1775 compared to $2100 \mathrm{~m}^{2} \mathrm{~g}^{-1}$ ) yet Darco KBG has superior performance (54 vs. $44 \%$ removal). Again, acid treatment is critical as the $\mathrm{NH}_{3}$-treated, wood-based Aquaguard catalyst had high surface area $\left(1600 \mathrm{~m}^{2} \mathrm{~g}^{-1}-\right.$ comparable to several effect materials), yet did not outperform the control. Moreover, the improvement in ODS performance observed for the acid-treated, wood-based carbons (40-70\% effectiveness) compared to the other carbons (10-15\% effectiveness) goes far beyond the differences in surface areas (approximately 1500-2000 $\mathrm{m}^{2} \mathrm{~g}^{-1}$ compared to $500-1500 \mathrm{~m}^{2} \mathrm{~g}^{-1}$ ). These observations indicate that surface area of the carbon materials is only one of several factors affecting their promotion ability.

Next, we considered pore size. As mentioned previously, carbon micro/mesoporosity has been linked to dibenzothiophene adsorption capacity.[54] For ODS, Gonzalez et al.[18] investigated performance of 2 activated carbons considered in this study (Norit SX-1 and MW 99-R-06), finding that the acid-treated wood-based carbon had about twice the micropore volume than the steam-treated peat carbon $\left(0.54 \mathrm{vs} 0.23 \mathrm{~cm}^{3}\right.$

$\left.\mathrm{g}^{-1}\right)$ and almost $10 \mathrm{x}$ more mesopore volume (0.60 vs $\left.0.07 \mathrm{~cm}^{3} \mathrm{~g}^{-1}\right)$. This suggests that 
mesopore volume may play an important role, as larger pores might provide better access for the BT molecules to the carbon surface. On the other hand, Gonzalez et al.[18] reported similar average pore diameters for the 2 carbons ( 31 and $27 \AA$, with the larger pore diameter corresponding to the steam-treated peat carbon, SX-1).

To investigate further, we measured pore volume and pore size using the nitrogen sorption method on representative subset of the carbons. Table 4 summarizes the results. The acid-treated, wood-based carbons have the highest pore volumes, ranging from 1.06$1.45 \mathrm{~cm}^{3} \mathrm{~g}^{-1}$, and average pore sizes ranging from 26 to $31 \AA$. Based on this, we can conclude that high pore volume and large pore sizes may be beneficial for ODS performance. However, the most effective ODS performer (HP-120) actually has the lowest pore volume of the various wood-based acid-treated carbons and an average pore size in the middle of the range. Moreover, the ammonia-treated wood-based carbon, Aquaguard, has the largest pore volume $\left(1.47 \mathrm{~cm}^{3} \mathrm{~g}^{-1}\right)$ and average pore size $(34 \AA)$ of any carbon analyzed - and yet, Aquarguard was found to be an ineffective ODS promoter (see Table 3). Based on the pore volume and pore size results, we conclude that molecular access alone - while necessary for ODS - is not sufficient to explain the observed differences in effectiveness. To explain the observed differences in performance, we turned to surface chemical and defect analysis methods.

\subsection{Presence of Surface Oxygen Species - DRIFTS and XPS}

Activated carbon surfaces can bear a variety of functional oxygen species which can be characterized using DRIFTS. Figure 1 shows a set of DRIFTS spectra of 5 representative carbon samples. Several sharp IR bands were observed for all 3 of the acidtreated, wood-based catalysts (HP120, Darco KBM, and MW-99-R-06), whereas the inactive carbons (Norit SX-1 is shown as representative in Figure 1) are featureless. 
Taking the analysis a step further, the band at $1700-1740 \mathrm{~cm}^{-1}$ is assigned to the stretching vibration of $\mathrm{C}=\mathrm{O}$ bond in $(-\mathrm{COOH})$ in carboxylic acids or in esters/aldehydes.[57, 68] When $\mathrm{C}=\mathrm{O}$ bonds in anhydride and lactone were conjugated with other double bonds and/or aromatic rings, their stretching bands are expected to appear at higher wave numbers.[69] Therefore, oxygen species in surface anhydride and lactone species probably exist in acid-treated wood-based carbon samples. The band at $1590 \mathrm{~cm}^{-1}$ is assigned to either to $\mathrm{C}=\mathrm{C}$ or $\mathrm{C}=\mathrm{O}$ conjugated present in in carboxyl carbonates or quinones. The $\mathrm{C}-\mathrm{O}$ stretching vibrating mode of ether or alcohol functionalities can be seen in the region between 1250 and $1270 \mathrm{~cm}^{-1}$.[70] All of these vibrational bands support the abundance of oxygen-bearing functional groups on the effective materials and their absence on other carbons.

In addition to DRIFTS, we performed XPS survey scans on representative carbon materials, finding that the $\mathrm{C} / \mathrm{O}$ ratio of the acid-treated, wood-based carbons was nearly twice that as found for the other carbon types. More details on the XPS analysis are provided in the Supporting Information.

\subsection{Surface Acidity - Boehm Titration and $\mathrm{NH}_{3}$-TPD}

We applied the Boehm titration method to determine the surface acidity of the selected carbon materials. Figure 2 contains a plot of surface acidity data obtained from the Boehm titration method superimposed on ODS performance data. The titration data show that each carbon contains phenolic, lactonic and carboxylic type acid sites. However, the density of acid sites and strengths varies, depending on the carbon source and activation treatment. All the acid treated, wood-based carbons (HP120, Darco KBG, and MW 99252-06) contain a large number of acid sites; only a small number of acid sites were detected on the other carbon samples. The Norit SX-1 and Pica B9 samples that show low 
ODS activity contain very low concentrations of carboxylic acid sites which is in agreement with the DRIFTS spectra shown in Figure 1. In fact, Figure 2 makes clear that the total amount of surface acid sites are almost linearly correlated with ODS performance. Base site concentration, on the other hand, has no effect on ODS performance.

In addition to Boehm titration, we analyzed representative carbons using $\mathrm{NH}_{3}$ TPD.[71] The full analysis is detailed in the Supporting Information. In summary, $\mathrm{NH}_{3}$ TPD indicated that the acid-treated, wood-based carbons had between 2 and 5-times higher concentrations of acid sites than the other carbons considered here and that the acid content of the acid-treated, wood-based carbons was more likely to be present as strong acid sites. On the other hand, $\mathrm{NH}_{3}$-TPD could not differentiate amongst the highly active wood-based carbons as effectively as Boehm titration. We suggest this is due to thermal decomposition of the carbon samples at elevated temperatures $\left(>600{ }^{\circ} \mathrm{C}\right)$ interfering with the TPD signal.[72] Nonetheless, taken together the Boehm titration and $\mathrm{NH}_{3}$-TPD results indicate surface acid sites to be a defining feature of the effective promoter materials.

\subsection{Defect Analysis - Raman Microspectroscopy}

We next turned to Raman microspectroscopy for characterizing short range disorder and potential electron structure changes that perturb the translational symmetry of the analyzed sample. Figure 3 shows the Raman spectra of several representative carbons. For each sample, two broad Raman bands, centered respectively at $1240-1360 \mathrm{~cm}^{-1}$ and $1585-$ $1660 \mathrm{~cm}^{-1}$, stand out. These two peaks are well-known in carbon materials and are typically termed the D and G bands, respectively.[64] Both bands belong to the first-order region of the Raman spectrum.[64] The position, area and intensity of these bands can indicate differences in the structural characteristics of the carbon material.[66, 73, 74] The D band 
peak at around $\sim 1300 \mathrm{~cm}^{-1}$ corresponds to the in-plane vibrations of $\mathrm{sp}^{2}$-bonded carbon with structural imperfections. $[64,75,76]$ Traditionally, the D band is used as a diagnostic either for structural disordering or structural defects.[73] The G band is related to the inplane vibrations of $\mathrm{sp}^{2}$-bonded crystalline carbon with graphite structure.

Overall, both the G and D band are relatively broad, indicating that the crystallite size of these carbons is very small and each sample contains many structural defects. Beyond this qualitative observation, we next undertook quantitative analysis of the Raman spectra using two approaches to correlate the Raman data with ODS performance: (1) fitting the D and G bands,[64] and (2) using a more sophisticated analysis[77] which divides the D peak into four modes (termed D1, D2, D3, and D4) to gain additional structural information. The most important results of both analysis methods are provided in Figure 4. First, in Figure 4a we show the results of the D/G analysis. Here, the acid-treated, wood-based carbons are differentiated from all other carbons by their low $D / G$ ratio of about $0.8 \pm 0.05$ compared to a D/G ratio of $1.1 \pm 0.1$ for other carbons. Figure 4 a indicates that a high concentration of defect sites is not necessary for ODS promotion.

Figure $4 \mathrm{~b}$ takes the analysis a step further by using the ratio of the D1 defect, which has been identified in the literature as belonging to graphene edges, to the D2 defect, which has been identified with graphene sheets.[65, 77] Figure $4 \mathrm{~b}$ shows that the most effective promoters - all of them acid-treated, wood-based carbons - have low D1/D2 in the 1-3 range. All other carbons have a D1/D2 ratio of 5 or greater. Figure 4b suggests that edge sites are not beneficial to ODS performance, implying that the ODS reaction does not require edge sites. Other ways of plotting the Raman data (e.g., the ratio of the D1 peak to the sum of the D1, D2, and G peaks, suggested in the literature[65] as a measure of the graphitization of the sample, did not yield clean correlations with ODS performance. We 
interpret this finding to mean that the edge/sheet ratio is the most important defect characteristic defining ODS activity.

\subsection{Combined Structural and Chemical Characterization - NEXAFS}

As a final analysis, the carbon samples were analyzed using NEXAFS as a powerful means of probing both order and chemical composition simultaneously. Figure 5 provides results obtained for representative carbons. Immediately apparent, the effective acidtreated, wood-based carbons show much broader features at 285 and $293 \mathrm{eV}$ compared to the other carbons. More specifically, the more active carbons have a broader peak at approximately $284-286 \mathrm{eV}$, indicative of a larger range of $\mathrm{C}=\mathrm{C} \pi^{*}$ structures.[66] Furthermore, the more active carbons have much lower intensity ratio of the $284-286 \mathrm{eV}$ band to the $286-288 \mathrm{eV}$ band. The latter is indicative of the existence of surface oxygen species $(\mathrm{C}=\mathrm{O}, \mathrm{C}-\mathrm{OH}, \mathrm{C}-\mathrm{O}$ etc),[66] which is consistent with the observation that elevated surface oxygen content is a defining chemical feature of the more active carbon materials.

In the NEXAFS spectra shown in Figure 5, both the bands at $285.3 \mathrm{eV}$ and $292.8 \mathrm{eV}$ indicate the $\mathrm{C}=\mathrm{C}$ bond in aromatic structures or long-range order of graphite structure. For both bands, the ineffective carbons have more pronounced features than do the effective materials. The observed trend suggests that the graphite structure with long-range order is not responsible for the ODS reaction. Defects can be present either as edge sites or in basal planes. In combination with the Raman characterization results, which showed that edge sites are not required for ODS activity, the NEXAFS data suggest that defects present in basal planes are associated with high ODS performance.

\subsection{Discussion}

To summarize the performance and characterization results, we found that activated carbons produced by acid treating wood were effective ODS promoters; all other materials 
tested (including an ammonia-treated wood-based carbon) were ineffective. Among the effective ODS promoters, we found substantial variability, with 2,3-DMBT oxidation ranging from 41 to $69 \%$ (with an uncertainty of $\pm 3 \%$ ). We therefore conclude that the experimental design to focus on incomplete BT removal (instead of the $>90 \%$ that the optimized process can achieve) was effective in differentiating the various promoters.

We then characterized the samples to identify features associated with effectiveness. Textural analysis indicated that surface area and pore volume likely play a role in determining effectiveness, but could not explain all of the observed ODS trends. Chemical and defect analysis revealed that effective materials share some common traits that the ineffective materials lack: 1) high concentration of oxygen-bearing functional groups (DRIFTS and C K-NEXAFS) and high surface oxygen content (XPS), 2) high concentration of surface acid groups (Boehm titration and $\mathrm{NH}_{3}-\mathrm{TPD}$ ), 3) high concentration of defects (C K-NEXAFS) in the basal planes, rather than edge sites (Raman).

Based on the combined data, we hypothesize that the primary means of activated carbon promotion of the ODS reaction is via reaction of carboxylic acids with $\mathrm{H}_{2} \mathrm{O}_{2}$ to form surface-bound percarboxylic acid species. The hypothesis of a percarboxylic acid active site is consistent with the literature on liquid-phase oxidation of sulfur thiophene comopounds.[15, 17, 78, 79] The ODS reaction is well understood to proceed by reaction of sulfur-bearing compounds with percarboxylic acid species formed by liquid phase reaction between a carboxylic acid (usually formic or acetic acid) and hydrogen peroxide.[78, 79] Further, ex-situ generation of surface-bound percarboxylic acids on a mesoporous silica surface has been shown to be an effective catalyst for oxidation of BT and DBT model compounds.[80] 
Concentrating the BT compounds and the percarboxylic acid sites is expected to have a strong accelerating effect on the ODS reaction. De Filippis et al.[61] and later Gonzalez et al.[18] studied the emulsion oxidation of fuel sulfur compounds by the performic acid oxidant, finding that mass transfer and partitioning of the water-soluble oxidant into the fuel phase were key rate determining steps. Likewise, various technologies relying on ultrasound-assisted ODS likely benefit from enhanced fuel-oxidant mass transfer.[52, 81-83] In a similar way, the surfactant-catalyst approach described by Can $\mathrm{Li}$ and his co-workers and shown effective for fuel ODS benefits from the increased local concentrations of reactants and catalyst.[20-23] In our system, adsorption of sulfur compounds to the carbon surface[45, 46] would increase their interactions with a surfacebound performic acid group.

In addition to the surface-bound percarboxylic acid hypothesis, we considered carbon particle stabilization of fuel/water emulsions to explain the observed trends. Partly hydrophilic activated carbon particles (as the effective carbons should be based on their high surface oxygen content) would be more likely to reside at the fuel-water interface than fully hydrophobic particles (as the ineffective carbons would be).[84-88] Specifically relevant to the activated carbon work, Kim et al.[86] recently reported the use of graphene oxide as a molecular-colloidal surfactant, citing the importance of both graphene edges and carboxylic sites as the source of its amphiphilic properties. In comparison with our work, the most effective activated carbons for ODS tend to also have high carboxylic acid surface groups yet have lower edge sites than the less effective materials; we take this as indication that surface generation of percarboxylic acids is the more important phenomenon and that fuel/water emulsion stabilization is of secondary importance. 
To investigate further, we measured the BT adsorption capacity of two representative activated carbon materials, MW 99-R-06 (an acid-treated, wood-based carbon) and Norit SX-1 (steam-treated, peat-based carbon). Activated carbon is well known as an adsorbent for DBT compounds; $[31,33,49,50,54,56]$ its use for BT adsorption has been scarcely reported. Here, we found the two adsorption capacities to be nearly equivalent at $3.5 \pm 0.5 \mathrm{mg} \mathrm{g}^{-1}$. In other words, the effective and ineffective carbon materials had indistinguishable BT adsorption capacity.

Based on maximization of $\pi-\pi$ interactions, the aromatic BT compounds should adsorb to the activated carbon basal planes.[30] This likely adsorption configuration explains why edge defect sites are not prominent in the effective carbon materials.[89] To take advantage of the proximity effect, BT compounds must adsorb to sites that readily access the percarboxylic acid sites. Therefore, we infer that the effective carbons must have defects present within the basal planes, a hypothesis that is consistent with the data from both C K-NEXAFS (which indicates that effective carbons have low long-range order) and Raman (which indicates that edge sites are not required for activity).

Here, we have used JP-8 with an approximate aromatic content of 20 vol\% for all tests; accordingly, we considered $\pi-\pi$ stacking competition between BT compounds and aromatic hydrocarbons on the carbon surface. In their work on $\pi-\pi$ interactions, Yang et al.[90] used simulations to show that binding of thiophene was preferred over benzene, a factor which may explain why our ODS treatment was effective for BT oxidation even in the presence of excess aromatic hydrocarbon content. Additionally, we have previously showed[18] that oxidation of fuel hydrocarbons is modest (less than several percent) during ODS treatment; however, the most likely compounds to be oxidized are aromatic. 
Preferential, yet still minimal, oxidation of aromatic hydrocarbons compared to aliphatic hydrocarbons may be consistent with competition for adsorption sites between hydrocarbon and sulfur-bearing aromatic compounds.

To pursue the mechanism further, we performed a final set of NEXAFS tests on HP120 that had been exposed to various treatments, including an acetonitrile wash (as a control), exposure to hydrogen peroxide (a second control), and ODS conditions. Figure 6 shows the C K-NEXAFS spectra of HP-120 before and after various treatment. As before, the virgin $\mathrm{C}$ K-NEXAFS spectrum features broad transitions at $285 \mathrm{eV}$ (assigned to $\mathrm{C}=\mathrm{C}$ $\pi^{*}$ sites in graphitic structures) and $292.4 \mathrm{eV}$ (assigned to C-C $\sigma^{*}$ bonds indicative of longrange order).[91] In addition, the weak $288.5 \mathrm{eV}$ peak is likely due to the presence of carboxylic acid species or other bearing oxygen species such as $\mathrm{C}-\mathrm{O}$ or $\mathrm{C}=\mathrm{O}$.[91-95] As expected, treatment with acetonitrile had minimal effect on the NEXAFS spectra; this test was performed as a control because acetonitrile was used in the following tests to remove residual weakly adsorbed volatile compounds from the carbon prior to NEAXAFS measurement. Likewise, treatment with just the oxidant, $\mathrm{H}_{2} \mathrm{O}_{2}$, also had minimal effect on the $\mathrm{C}(1 \mathrm{~s})$ feature, suggesting that carbon treatment with only $\mathrm{H}_{2} \mathrm{O}_{2}$ is insufficient to generate the surface oxygen functional species that may be responsible for the ODS reaction. This observation could be consistent with the known catalytic effect of $\mathrm{H}^{+}$ions on percarboxylic acid formation.[61]

After the ODS reaction, the C(1s) XANES spectrum shows a significant intensity increase of the $288.5 \mathrm{eV}$ peak, which we attribute to formation of surface oxygen species, and a strong decrease of the $\sigma^{*}$ band at $292 \mathrm{eV}$, which we attribute to the partial loss of the graphite excitonic $\sigma^{*}$ peak. The decrease of the $\sigma^{*}$ resonance might result from a partial loss of translational symmetry within the plane,[96] as would be expected for formation of 
oxygen-bearing species in the basal planes. With this in mind, the distinct peak found at $288.5 \mathrm{eV}$ is likely due to oxidation of carbon defects to generate carboxylic or percarboxylic acids attached to the basal planes.[73]

Taken together, the $\mathrm{C}$ K-NEXAFS results from the ODS treated carbon are consistent with the suggestion that we have forwarded here: carbon materials promote ODS by formation of percarboxylic acid species originating in basal plane defects. The aromatic sulfur species adsorb to the basal planes to maximize $\pi-\pi$ interaction, thereby increasing their local concentration. The oxidized species can then desorb, making sites available. Adsorption alone is not sufficient as the BT adsorption capacity of effective and ineffective materials is similar. Instead, the combination of surface oxidant and adsorbent co-located on the carbon basal plane can rationalize the observed differences in performance observed for the various activated carbons we have examined here. Future work should be performed to systematically introduce oxygen bearing defects internal to carbon basal lanes and to evaluate these materials for oxidation performance.

\section{Conclusions}

Acid-treated wood-based carbons are inexpensive and effective promoters for ODS of hydrocarbon fuels, including JP-8. Textural properties, the presence of surface functional species, surface acidity, and structural defect sites significantly influence the ODS activity. High surface area and pore volume are required for effective promoters, but not sufficient. In addition, the carbon surface must have a high concentration of surface acidity and surface oxygen groups in general. Defect sites should be present within the basal planes, rather than as edge sites. Based on these findings, we infer that ODS promotion occurs after formation of percarboxylic acid sites within the carbon basal planes. Adsorption of 
aromatic sulfur compounds is preferred within the basal planes, as this configuration maximizes $\pi-\pi$ interaction. The result is a high local concentration of the aromatic sulfur reactants relative to the surface-bound percarboxylic acid complex. NEXAFS analysis of a carbon post-reaction provided supporting information for this description.

Acknowledgments: The authors thank the DoD (Army Research Office) for support (contracts \# W911NF-07-C-0068 and W911NF-08-C-0063). Peter Fedkiw (ARO and North Carolina State University) and Robert Mantz (ARO) provided technical guidance to define program goals. Robert Allen of the Air Force Fuels Laboratory provided a sample of JP-8 used for desulfurization experiments. J.A. Wang thanks CONACyT-Mexico for providing financial support for his sabbatical year at Worcester Polytechnic Institute, Worcester, MA.

\section{References.}

[1] ASTM, Standard Specification for Diesel Fuel Oils, in, ASTM International, West Conshohocken, PA, 2015.

[2] C.S. Song, An overview of new approaches to deep desulfurization for ultra-clean gasoline, diesel fuel and jet fuel, Catalysis Today, 86 (2003) 211-263.

[3] M.F. Ali, A. Al-Malki, B. El-Ali, G. Martinie, M.N. Siddiqui, Deep desulphurization of gasoline and diesel fuels using non-hydrogen consuming techniques, Fuel, 85 (2006) 13541363.

[4] C. Song, X. Ma, New design approaches to ultra-clean diesel fuels by deep desulfurization and deep dearomatization, Applied Catalysis B: Environmental, 41 (2003) 207-238.

[5] V.M. Bhandari, C.H. Ko, J.G. Park, S.-S. Han, S.-H. Cho, J.-N. Kim, Desulfurization of diesel using ion-exchanged zeolites, Chemical Engineering Science, 61 (2006) 2599-2608.

[6] J.H. Kim, X. Ma, A. Zhou, C. Song, Ultra-deep desulfurization and denitrogenation of diesel fuel by selective adsorption over three different adsorbents: a study on adsorptive selectivity and mechanism, Catalysis Today, 111 (2006) 74-83.

[7] H.-J. Jeon, C.H. Ko, S.H. Kim, J.-N. Kim, Removal of refractory sulfur compounds in diesel using activated carbon with controlled porosity, Energy \& Fuels, 23 (2009) 25372543.

[8] Heavy-Duty Engine and Vehicle Standards and Highway Diesel Fuel Sulfur Control Requirements, in, US EPA, 2000. 
[9] Heavy-Duty Engine and Vehicle Standards and Highway Diesel Fuel Sulfur Control Requirements, in, US EPA, 2001.

[10] P. de Peinder, T. Visser, R. Wagemans, J. Blomberg, H. Chaabani, F. Soulimani, B.M. Weckhuysen, Sulfur Speciation of Crude Oils by Partial Least Squares Regression Modeling of Their Infrared Spectra, Energy \& Fuels, 24 (2010) 557-562.

[11] E. Ito, J.A.R. van Veen, On novel processes for removing sulphur from refinery streams, Catalysis Today, 116 (2006) 446-460.

[12] I. Babich, J. Moulijn, Science and technology of novel processes for deep desulfurization of oil refinery streams: a review is, Fuel, 82 (2003) 607-631.

[13] I. Mochida, K. Choi, An overview of hydrodesulfurization and hydrodenitrogenation, Journal of the Japan Petroleum Institute, 47 (2004) 145-163.

[14] H. Topsøe, B.S. Clausen, F.E. Massoth, Hydrotreating catalysis, Springer, 1996.

[15] K. Yazu, M. Makino, K. Ukegawa, Oxidative desulfurization of diesel oil with hydrogen peroxide in the presence of acid catalyst in diesel oil/acetic acid biphasic system, Chemistry Letters, 33 (2004) 1306-1307.

[16] V.R. Tumula, S. Bondwal, P. Bisht, C. Pendem, J. Kumar, Oxidation of sulfides to sulfones with hydrogen peroxide in the presence of acetic acid and Amberlyst 15, Reaction Kinetics, Mechanisms and Catalysis, 107 (2012) 449-466.

[17] U. Arellano, J. Wang, M. Timko, L. Chen, S.P. Carrera, M. Asomoza, O.G. Vargas, M. Llanos, Oxidative removal of dibenzothiophene in a biphasic system using sol-gel $\mathrm{Fe}$ TiO 2 catalysts and H 2 O 2 promoted with acetic acid, Fuel, 126 (2014) 16-25.

[18] L.A. Gonzalez, P. Kracke, W.H. Green, J.W. Tester, L.M. Shafer, M.T. Timko, Oxidative Desulfurization of Middle-Distillate Fuels Using Activated Carbon and Power Ultrasound, Energy \& Fuels, 26 (2012) 5164-5176.

[19] M.T. Timko, E. Schmois, P. Patwardhan, Y. Kida, C.A. Class, W.H. Green, R.K. Nelson, C.M. Reddy, Response of different types of sulfur compounds to oxidative desulfurization of jet fuel, Energy \& Fuels, 28 (2014) 2977-2983.

[20] J.B. Gao, S.G. Wang, Z.X. Jiang, H.Y. Lu, Y.X. Yang, F. Jing, C. Li, Deep desulfurization from fuel oil via selective oxidation using an amphiphilic peroxotungsten catalyst assembled in emulsion droplets, Journal of Molecular Catalysis a-Chemical, 258 (2006) 261-266.

[21] C. Li, J.B. Gao, Z.X. Jiang, S.G. Wang, H.Y. Lu, Y.X. Yang, F. Jing, Selective oxidations on recoverable catalysts assembled in emulsions, Topics in Catalysis, 35 (2005) $169-175$.

[22] C. Li, Z.X. Jiang, J.B. Gao, Y.X. Yang, S.J. Wang, F.P. Tian, F.X. Sun, X.P. Sun, P.L. Ying, C.R. Han, Ultra-deep desulfurization of diesel: Oxidation with a recoverable catalyst assembled in emulsion, Chemistry-a European Journal, 10 (2004) 2277-2280.

[23] H.Y. Lu, J.B. Gao, Z.X. Jiang, F. Jing, Y.X. Yano, G. Wang, C. Li, Ultra-deep desulfurization of diesel by selective oxidation with [C18H37N(CH3)(3)](4)[H2NaPW10O36] catalyst assembled in emulsion droplets, Journal of Catalysis, 239 (2006) 369-375.

[24] S. Maghsoudi, M. Vossoughi, A. Kheirolomoom, E. Tanaka, S. Katoh, Biodesulfurization of hydrocarbons and diesel fuels by Rhodococcus sp. strain P32C1, Biochemical Engineering Journal, 8 (2001) 151-156.

[25] D.J. Monticello, Biodesulfurization and the upgrading of petroleum distillates, Current Opinion in Biotechnology, 11 (2000) 540-546. 
[26] M. Soleimani, A. Bassi, A. Margaritis, Biodesulfurization of refractory organic sulfur compounds in fossil fuels, Biotechnology advances, 25 (2007) 570-596.

[27] A. Abin-Fuentes, J.C. Leung, M.E.S. Mohamed, D.I. Wang, K.L. Prather, Rate-limiting step analysis of the microbial desulfurization of dibenzothiophene in a model oil system, Biotechnology and bioengineering, 111 (2014) 876-884.

[28] A. Abin-Fuentes, M.E.-S. Mohamed, D.I. Wang, K.L. Prather, Exploring the mechanism of biocatalyst inhibition in microbial desulfurization, Applied and environmental microbiology, 79 (2013) 7807-7817.

[29] A.J. Hernandez-Maldonado, R.T. Yang, Desulfurization of transportation fuels by adsorption, Catalysis Reviews-Science and Engineering, 46 (2004) 111-150.

[30] Y.H. Wang, F.H. Yang, R.T. Yang, J.M. Heinzel, A.D. Nickens, Desulfurization of high-sulfur jet fuel by pi-complexation with copper and palladium halide sorbents, Industrial \& Engineering Chemistry Research, 45 (2006) 7649-7655.

[31] C.O. Ania, T.J. Bandosz, Importance of structural and chemical heterogeneity of activated carbon surfaces for adsorption of dibenzothiophene, Langmuir, 21 (2005) 77527759.

[32] C.O. Ania, T.J. Bandosz, Metal-loaded polystyrene-based activated carbons as dibenzothiophene removal media via reactive adsorption, Carbon, 44 (2006) 2404-2412.

[33] C.O. Ania, T.J. Bandosz, Sodium on the surface of activated carbons as a factor enhancing reactive adsorption of dibenzothiophene, Energy \& Fuels, 20 (2006) 1076-1080.

[34] X.L. Ma, L. Sun, C.S. Song, A new approach to deep desulfurization of gasoline, diesel fuel and jet fuel by selective adsorption for ultra-clean fuels and for fuel cell applications, Catalysis Today, 77 (2002) 107-116.

[35] S. Velu, X.L. Ma, C.S. Song, M. Namazian, S. Sethuraman, G. Venkataraman, Desulfurization of JP-8 jet fuel by selective adsorption over a Ni-based adsorbent for micro solid oxide fuel cells, Energy \& Fuels, 19 (2005) 1116-1125.

[36] A.N. Zhou, X.L. Ma, C.S. Song, Liquid-phase adsorption of multi-ring thiophenic sulfur compounds on carbon materials with different surface properties, Journal of Physical Chemistry B, 110 (2006) 4699-4707.

[37] Z. Jiang, Y. Liu, X. Sun, F. Tian, F. Sun, C. Liang, W. You, C. Han, C. Li, Activated carbons chemically modified by concentrated $\mathrm{H} 2 \mathrm{SO} 4$ for the adsorption of the pollutants from wastewater and the dibenzothiophene from fuel oils, Langmuir, 19 (2003) 731-736.

[38] W. Zhang, H. Liu, Q. Xia, Z. Li, Enhancement of dibenzothiophene adsorption on activated carbons by surface modification using low temperature oxygen plasma, Chemical Engineering Journal, 209 (2012) 597-600.

[39] J.M. Palomino, D.T. Tran, J.L. Hauser, H. Dong, S.R. Oliver, Mesoporous silica nanoparticles for high capacity adsorptive desulfurization, Journal of Materials Chemistry A, 2 (2014) 14890-14895.

[40] J.M. Palomino, D.T. Tran, A.R. Kareh, C.A. Miller, J.M. Gardner, H. Dong, S.R. Oliver, Zirconia-silica based mesoporous desulfurization adsorbents, Journal of Power Sources, 278 (2015) 141-148.

[41] D.T. Tran, Z.W. Dunbar, D. Chu, Regenerable sulfur adsorbent for liquid phase JP-8 fuel using gold/silica based materials, International journal of hydrogen energy, 37 (2012) 10430-10434.

[42] S. Zhang, Q. Zhang, Z.C. Zhang, Extractive desulfurization and denitrogenation of fuels using ionic liquids, Industrial \& engineering chemistry research, 43 (2004) 614-622. 
[43] A. Bösmann, L. Datsevich, A. Jess, A. Lauter, C. Schmitz, P. Wasserscheid, Deep desulfurization of diesel fuel by extraction with ionic liquids, Chemical Communications, (2001) 2494-2495.

[44] C. Li, D. Li, S. Zou, Z. Li, J. Yin, A. Wang, Y. Cui, Z. Yao, Q. Zhao, Extraction desulfurization process of fuels with ammonium-based deep eutectic solvents, Green Chemistry, 15 (2013) 2793-2799.

[45] G.X. Yu, S.X. Lu, H. Chen, Z.N. Zhu, Oxidative desulfurization of diesel fuels with hydrogen peroxide in the presence of activated carbon and formic acid, Energy \& Fuels, 19 (2005) 447-452.

[46] G.X. Yu, S.X. Lu, H. Chen, Z.N. Zhu, Diesel fuel desulfurization with hydrogen peroxide promoted by formic acid and catalyzed by activated carbon, Carbon, 43 (2005) 2285-2294.

[47] G.X. Yu, R.X. Zhou, J.B. Li, X.L. Zhou, C.L. Li, L.F. Chen, J.A. Wang, Oxidative Removal of Dibenzothiophene by $\mathrm{H} 2 \mathrm{O} 2$ over Activated Carbon-Supported Phosphotungstic Acid Catalysts, in: Advanced Materials Research, Trans Tech Publ, 2010, pp. 126-132.

[48] N.F. Nejad, E. Shams, M. Amini, J. Bennett, Synthesis of magnetic mesoporous carbon and its application for adsorption of dibenzothiophene, Fuel Processing Technology, 106 (2013) 376-384.

[49] Q. Wang, X. Liang, W. Qiao, C. Liu, X. Liu, L. Zhan, L. Ling, Preparation of polystyrene-based activated carbon spheres with high surface area and their adsorption to dibenzothiophene, Fuel Processing Technology, 90 (2009) 381-387.

[50] A. Zhou, X. Ma, C. Song, Effects of oxidative modification of carbon surface on the adsorption of sulfur compounds in diesel fuel, Applied Catalysis B: Environmental, 87 (2009) 190-199.

[51] J. Xiao, Z. Li, B. Liu, Q. Xia, M. Yu, Adsorption of benzothiophene and dibenzothiophene on ion-impregnated activated carbons and ion-exchanged $\mathrm{Y}$ zeolites, Energy \& Fuels, 22 (2008) 3858-3863.

[52] H. Mei, B.W. Mei, T.F. Yen, A new method for obtaining ultra-low sulfur diesel fuel via ultrasound assisted oxidative desulfurization, Fuel, 82 (2003) 405-414.

[53] O. Etemadi, T.F. Yen, Surface characterization of adsorbents in ultrasound-assisted oxidative desulfurization process of fossil fuels, Journal of Colloid and Interface Science, 313 (2007) 18-25.

[54] K.S. Triantafyllidis, E.A. Deliyanni, Desulfurization of diesel fuels: Adsorption of 4,6DMDBT on different origin and surface chemistry nanoporous activated carbons, Chemical Engineering Journal, 236 (2014) 406-414.

[55] G.X. Yu, M. Jin, J. Sun, X.L. Zhou, L.F. Chen, J.A. Wang, Oxidative modifications of rice hull-based carbons for dibenzothiophene adsorptive removal, Catalysis Today, 212 (2013) 31-37.

[56] M. Seredych, J. Lison, U. Jans, T.J. Bandosz, Textural and chemical factors affecting adsorption capacity of activated carbon in highly efficient desulfurization of diesel fuel, Carbon, 47 (2009) 2491-2500.

[57] J. Collins, T. Ngo, D. Qu, M. Foster, Spectroscopic investigations of sequential nitric acid treatments on granulated activated carbon: Effects of surface oxygen groups on $\pi$ density, Carbon, 57 (2013) 174-183. 
[58] X.X. Wu, A.K. Kercher, V. Schwartz, S.H. Overbury, T.R. Armstrong, Activated carbons for selective catalytic oxidation of hydrogen sulfide to sulfur, Carbon, 43 (2005) $1087-1090$.

[59] X.X. Wu, V. Schwartz, S.H. Overbury, T.R. Armstrong, Desulfurization of gaseous fuels using activated carbons as catalysts for the selective oxidation of hydrogen sulfide, Energy \& Fuels, 19 (2005) 1774-1782.

[60] J.L. Figueiredo, M.F.R. Pereira, The role of surface chemistry in catalysis with carbons, Catalysis Today, 150 (2010) 2-7.

[61] P. De Filippis, M. Scarsella, N. Verdone, Peroxyformic Acid Formation: A Kinetic Study, Industrial \& Engineering Chemistry Research, 48 (2009) 1372-1375.

[62] I.C. Lee, H.C. Ubanylonwu, Determination of sulfur contaminants in military jet fuels, Fuel, 87 (2008) 312-318.

[63] D.D. Link, J.P. Baltrus, K.S. Rothenberger, Class- and structure-specific separation, analysis, and identification techniques for the characterization of the sulfur components of JP-8 aviation fuel, Energy \& Fuels, 17 (2003) 1292-1302.

[64] A.C. Ferrari, J. Robertson, Interpretation of Raman spectra of disordered and amorphous carbon, Physical Review B, 61 (2000) 14095-14107.

[65] O. Beyssac, B. Goffé, J.-P. Petitet, E. Froigneux, M. Moreau, J.-N. Rouzaud, On the characterization of disordered and heterogeneous carbonaceous materials by Raman spectroscopy, Spectrochimica Acta Part A: Molecular and Biomolecular Spectroscopy, 59 (2003) 2267-2276.

[66] S. Bernard, O. Beyssac, K. Benzerara, N. Findling, G. Tzvetkov, G. Brown, XANES, Raman and XRD study of anthracene-based cokes and saccharose-based chars submitted to high-temperature pyrolysis, Carbon, 48 (2010) 2506-2516.

[67] H.P. Boehm, Surface oxides on carbon and their analysis: a critical assessment, Carbon, 40 (2002) 145-149.

[68] J. Xiao, Z. Liu, K. Kim, Y. Chen, J. Yan, Z. Li, W. Wang, S/O-Functionalities on Modified Carbon Materials Governing Adsorption of Water Vapor, The Journal of Physical Chemistry C, 117 (2013) 23057-23065.

[69] G. Mul, J.P.A. Neeft, F. Kapteijn, J.A. Moulijn, The formation of carbon surface oxygen complexes by oxygen and ozone. The effect of transition metal oxides, Carbon, 36 (1998) 1269-1276.

[70] J. Zawadzki, Infrared-spectroscopy in surface-chemistry of carbons, Chemistry and physics of carbon, 21 (1989) 147-380.

[71] J.R. Kastner, J. Miller, D.P. Geller, J. Locklin, L.H. Keith, T. Johnson, Catalytic esterification of fatty acids using solid acid catalysts generated from biochar and activated carbon, Catalysis Today, 190 (2012) 122-132.

[72] J.L. Figueiredo, M.F.R. Pereira, M.M.A. Freitas, J.J.M. Órfão, Modification of the surface chemistry of activated carbons, Carbon, 37 (1999) 1379-1389.

[73] N. Shimodaira, A. Masui, Raman spectroscopic investigations of activated carbon materials, Journal of Applied Physics, 92 (2002) 902-909.

[74] T. Jawhari, A. Roid, J. Casado, Raman spectroscopic characterization of some commercially available carbon black materials, Carbon, 33 (1995) 1561-1565.

[75] A. Gupta, G. Chen, P. Joshi, S. Tadigadapa, Eklund, Raman Scattering from HighFrequency Phonons in Supported n-Graphene Layer Films, Nano Letters, 6 (2006) 26672673. 
[76] S.D.M. Brown, A. Jorio, M.S. Dresselhaus, G. Dresselhaus, Observations of the Itextit $\{$ D $\}$-band feature in the Raman spectra of carbon nanotubes, Physical Review B, 64 (2001) 073403.

[77] A. Sadezky, H. Muckenhuber, H. Grothe, R. Niessner, U. Pöschl, Raman microspectroscopy of soot and related carbonaceous materials: Spectral analysis and structural information, Carbon, 43 (2005) 1731-1742.

[78] S. Otsuki, T. Nonaka, N. Takashima, W.H. Qian, A. Ishihara, T. Imai, T. Kabe, Oxidative desulfurization of light gas oil and vacuum gas oil by oxidation and solvent extraction, Energy \& Fuels, 14 (2000) 1232-1239.

[79] M. Te, C. Fairbridge, Z. Ring, Oxidation reactivities of dibenzothiophenes in polyoxometalate/ $\mathrm{H} 2 \mathrm{O} 2$ and formic acid/H2O2 systems, Applied Catalysis a-General, 219 (2001) 267-280.

[80] P. De Filippis, M. Scarsella, Functionalized hexagonal mesoporous silica as an oxidizing agent for the oxidative desulfurization of organosulfur compounds, Industrial \& Engineering Chemistry Research, 47 (2008) 973-975.

[81] M.W. Wan, T.F. Yen, Enhance efficiency of tetraoctylarnmoniurn fluoride applied to ultrasound-assisted oxidative desulfurization (UAOD) process, Applied Catalysis aGeneral, 319 (2007) 237-245.

[82] A. Deshpande, A. Bassi, A. Prakash, Ultrasound-assisted, base-catalyzed oxidation of 4,6-dimethyldibenzothiophene in a biphasic diesel-acetonitrile system, Energy \& Fuels, 19 (2005) 28-34.

[83] T.F. Yen, H.M. Lu, H. Mei, New method for obtaining diesel fuel with ultra-low sulfur content: Ultrasound oxidation, Abstracts of Papers of the American Chemical Society, 221 (2001) U221-U221.

[84] W.B. Wan, Z.B. Zhao, T.C. Hughes, B.Q. Qian, S.H. Peng, X.J. Hao, J.S. Qiu, Graphene oxide liquid crystal Pickering emulsions and their assemblies, Carbon, 85 (2015) $16-23$.

[85] S.C. Thickett, P.B. Zetterlund, Graphene oxide (GO) nanosheets as oil-in-water emulsion stabilizers: Influence of oil phase polarity, Journal of Colloid and Interface Science, 442 (2015) 67-74.

[86] J. Kim, L.J. Cote, F. Kim, W. Yuan, K.R. Shull, J.X. Huang, Graphene Oxide Sheets at Interfaces, Journal of the American Chemical Society, 132 (2010) 8180-8186.

[87] R. Aveyard, B.P. Binks, J.H. Clint, Emulsions stabilised solely by colloidal particles, Advances in Colloid and Interface Science, 100 (2003) 503-546.

[88] T. Sakai, Surfactant-free emulsions, Current Opinion in Colloid \& Interface Science, 13 (2008) 228-235.

[89] G.S. Foo, C. Sievers, Synergistic Effect between Defect Sites and Functional Groups on the Hydrolysis of Cellulose over Activated Carbon, ChemSusChem, 8 (2015) 534-543.

[90] R.T. Yang, A. Takahashi, F.H. Yang, New sorbents for desulfurization of liquid fuels by $\pi$-complexation, Industrial \& engineering chemistry research, 40 (2001) 6236-6239.

[91] C. Morant, R. Torres, I. Jimenez, J.M. Sanz, E. Elizalde, Characterization of NitrogenDoped Carbon Nanotubes by Atomic Force Microscopy, X-ray Photoelectron Spectroscopy and X-ray Absorption Near Edge Spectroscopy, Journal of Nanoscience and Nanotechnology, 9 (2009) 3633-3638.

[92] S.G. Urquhart, H. Ade, Trends in the Carbonyl Core (C 1S, O 1S) $\rightarrow \pi^{*} \mathrm{C}=\mathrm{O}$ Transition in the Near-Edge X-ray Absorption Fine Structure Spectra of Organic Molecules, The Journal of Physical Chemistry B, 106 (2002) 8531-8538. 
[93] J.A. Brandes, G.D. Cody, D. Rumble, P. Haberstroh, S. Wirick, Y. Gelinas, Carbon Kedge XANES spectromicroscopy of natural graphite, Carbon, 46 (2008) 1424-1434.

[94] I. Jiménez, R. Gago, J.M. Albella, L.J. Terminello, X-Ray absorption studies of bonding environments in graphitic carbon nitride, Diamond and Related Materials, 10 (2001) 1170-1174.

[95] I. Jiménez, R. Gago, J.M. Albella, Fine structure at the X-ray absorption $\pi^{*}$ and $\sigma^{*}$ bands of amorphous carbon, Diamond and Related Materials, 12 (2003) 110-115.

[96] J. Zhong, L. Song, D. Yan, Z. Wu, C. Wang, S. Xie, H. Qian, A XANES characterization of structural defects in single-walled carbon nanotubes, Radiation Physics and Chemistry, 75 (2006) 1861-1865. 
Table 1. Select Data for Activated Carbon Samples.

\begin{tabular}{|c|c|c|c|}
\hline Sample ID & Manufacturer & $\begin{array}{l}\text { Carbon } \\
\text { Source }\end{array}$ & $\begin{array}{c}\text { Activation } \\
\text { Method }\end{array}$ \\
\hline $\begin{array}{c}\text { MW } 2001- \\
\text { R-06 }\end{array}$ & Meadwestvaco & wood & $\begin{array}{c}\text { phosphoric } \\
\text { acid }\end{array}$ \\
\hline $\begin{array}{c}\text { MW 252-R- } \\
07\end{array}$ & Meadwestvaco & wood & $\begin{array}{c}\text { phosphoric } \\
\text { acid }\end{array}$ \\
\hline $\begin{array}{c}\text { MW 99-R- } \\
06\end{array}$ & Meadwestvaco & wood & $\begin{array}{c}\text { phosphoric } \\
\text { acid }\end{array}$ \\
\hline Aquaguard & Meadwestvaco & wood & ammonia \\
\hline Darco KBG & Norit & wood & $\begin{array}{c}\text { phosphoric } \\
\text { acid }\end{array}$ \\
\hline Darco KBM & Norit & wood & $\begin{array}{c}\text { phosphoric } \\
\text { acid }\end{array}$ \\
\hline SX-1 & Norit & peat & thermal \\
\hline SX Ultra & Norit & peat & thermal \\
\hline Darco S-51 & Norit & lignite coal & steam \\
\hline Pac 200 & Norit & coal & $\begin{array}{c}\text { not } \\
\text { disclosed }\end{array}$ \\
\hline HP120 & Pica & wood & $\begin{array}{c}\text { phosphoric } \\
\text { acid }\end{array}$ \\
\hline B9 & Pica & wood & steam \\
\hline
\end{tabular}


Table 2. Typical ODS Conditions for Shaker Experiments

\begin{tabular}{|l|l|}
\hline Fuel & $10 \mathrm{~mL} \mathrm{JP}-8\left(717 \mathrm{ppm}_{\mathrm{w}}\right.$ sulfur $)$ \\
Oxidant & $2 \mathrm{~mL}$ of $30 \mathrm{vol} \% \mathrm{H}_{2} \mathrm{O}_{2}$ plus \\
formic acid \\
Rearbon mass & $0.1 \mathrm{~g}$ \\
Reaction & $40 \mathrm{~mL}$ vials \\
Temperature & $25{ }^{\circ} \mathrm{C}$ \\
Reaction & $4 \mathrm{hr}$ \\
Time & \\
\hline
\end{tabular}


Table 3. ODS Performance Data and Surface Area for Activated Carbon Samples.

\begin{tabular}{|c|c|c|c|}
\hline Carbon Type & Sample ID & $\begin{array}{c}\text { 2,3-DMBT } \\
\text { Removal }^{\mathrm{a}, \mathrm{b}}(\%)\end{array}$ & $\begin{array}{c}\text { BET Surface Area } \\
\left(\mathrm{m}^{2} \mathrm{~g}^{-1}\right)\end{array}$ \\
\hline \multirow{6}{*}{$\begin{array}{c}\text { Acid-Treated, } \\
\text { Wood-Based } \\
\text { Carbons }\end{array}$} & HP120 & 69 & 2200 \\
\hline & Darco KBG & 54 & 1775 \\
\hline & MW 252-R-07 & 48 & \\
\hline & MW 99-R-06 & 44 & 2100 \\
\hline & Darco KBM & 42 & 1000 \\
\hline & MW 2001-R-06 & 41 & 2100 \\
\hline \multirow{5}{*}{ Other $\mathrm{c}$} & SX Ultra & 14 & 1075 \\
\hline & SX-1 & 11 & 800 \\
\hline & B9 & 11 & 1100 \\
\hline & Pac 200 & 10 & \\
\hline & Aquaguard & 9 & 1600 \\
\hline
\end{tabular}

a 2,3-dimethylbenzothiophene removal (\%) from JP-8 jet fuel, $\pm 3 \%$ based on repeat runs.

${ }^{\mathrm{b}}$ ODS reaction conditions are provided in Table 2.

${ }^{\mathrm{c}}$ blanks denote missing data. 
Table 4. Pore volume and pore size data for representative carbons

\begin{tabular}{|llcc|}
\hline Carbon Type & Sample & $\begin{array}{c}\text { Pore Volume } \\
\left(\mathrm{cm}^{3} \mathrm{~g}^{-1}\right)\end{array}$ & $\begin{array}{c}\text { Average Pore } \\
\text { Size }(\AA)\end{array}$ \\
\hline Acid-Treated, & MW 99-R-06 & 1.45 & 26 \\
Wood-Based & MW 2001-R-06 & 1.26 & 31 \\
Carbons & HP-120 & 1.17 & 29 \\
& Darco-KBM & 1.06 & 28 \\
\hline Other carbon & Norit SX-1 & 0.59 & 24 \\
types & Norit SX Ultra & 0.86 & 25 \\
& Aquaguard & 1.47 & 34 \\
\hline
\end{tabular}




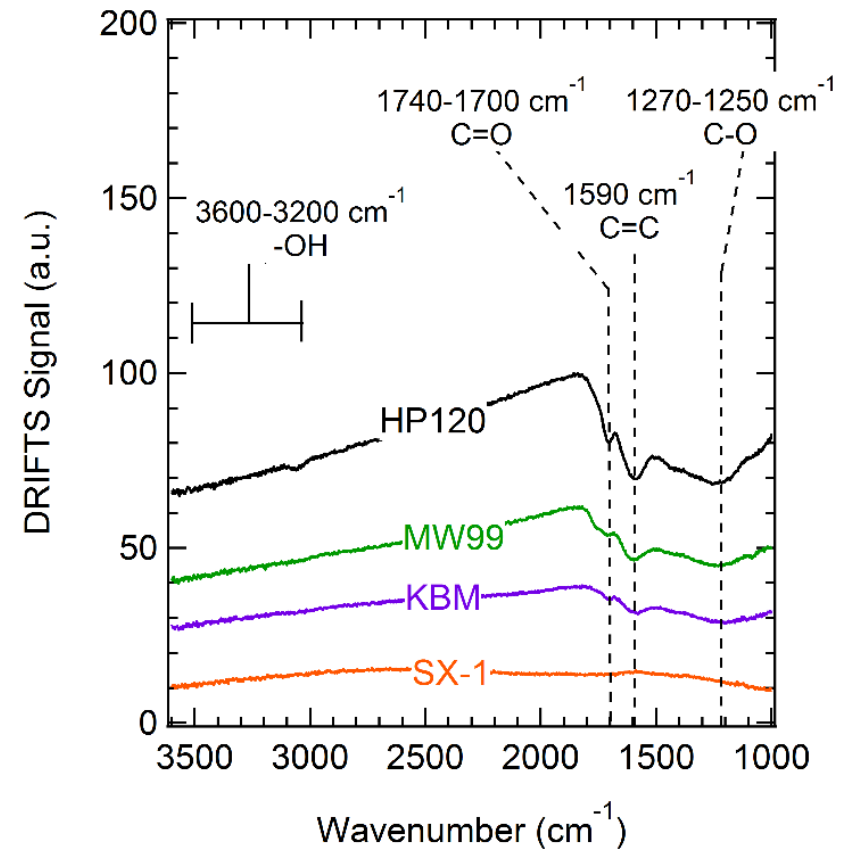

Figure 1. DRIFTS spectra of representative carbon samples 


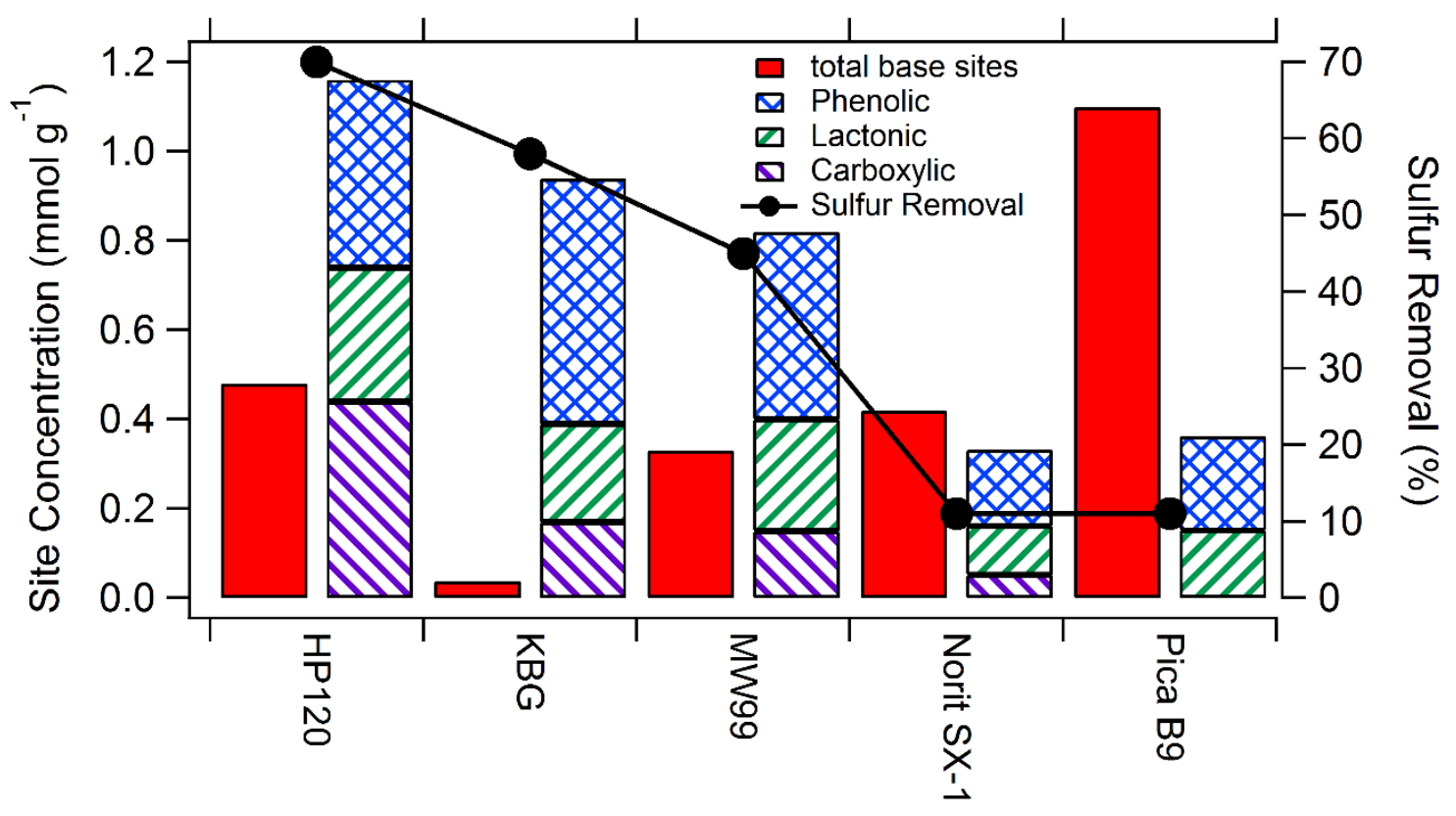

Figure 2. Boehm titration data for representative carbons plotted superimposed on 2,3-

DMBT removal performance. 


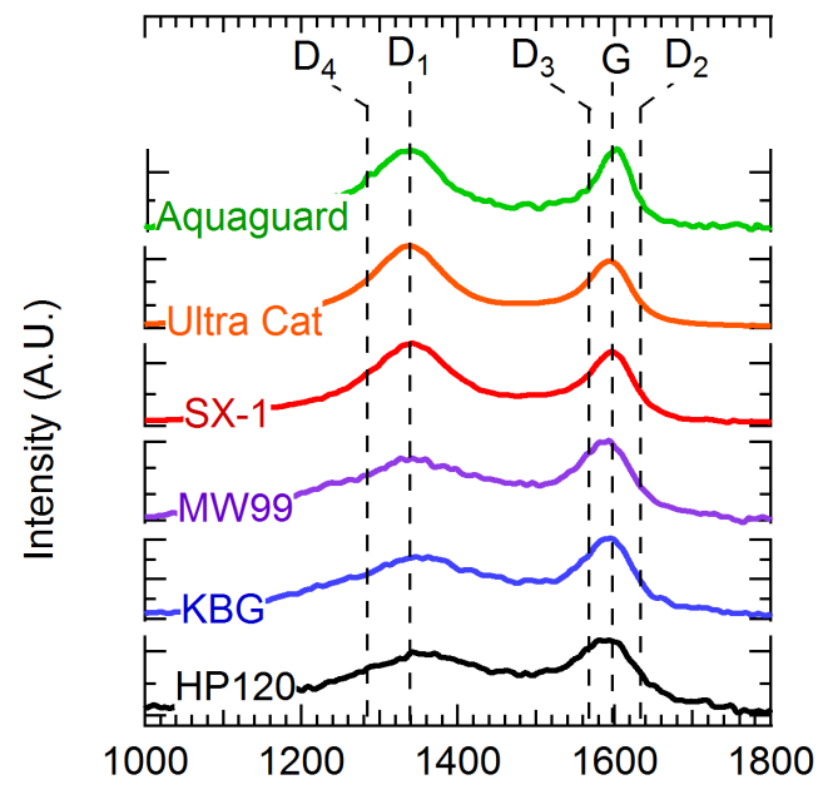

Figure 3. Representative Raman spectra for activated carbon materials. 

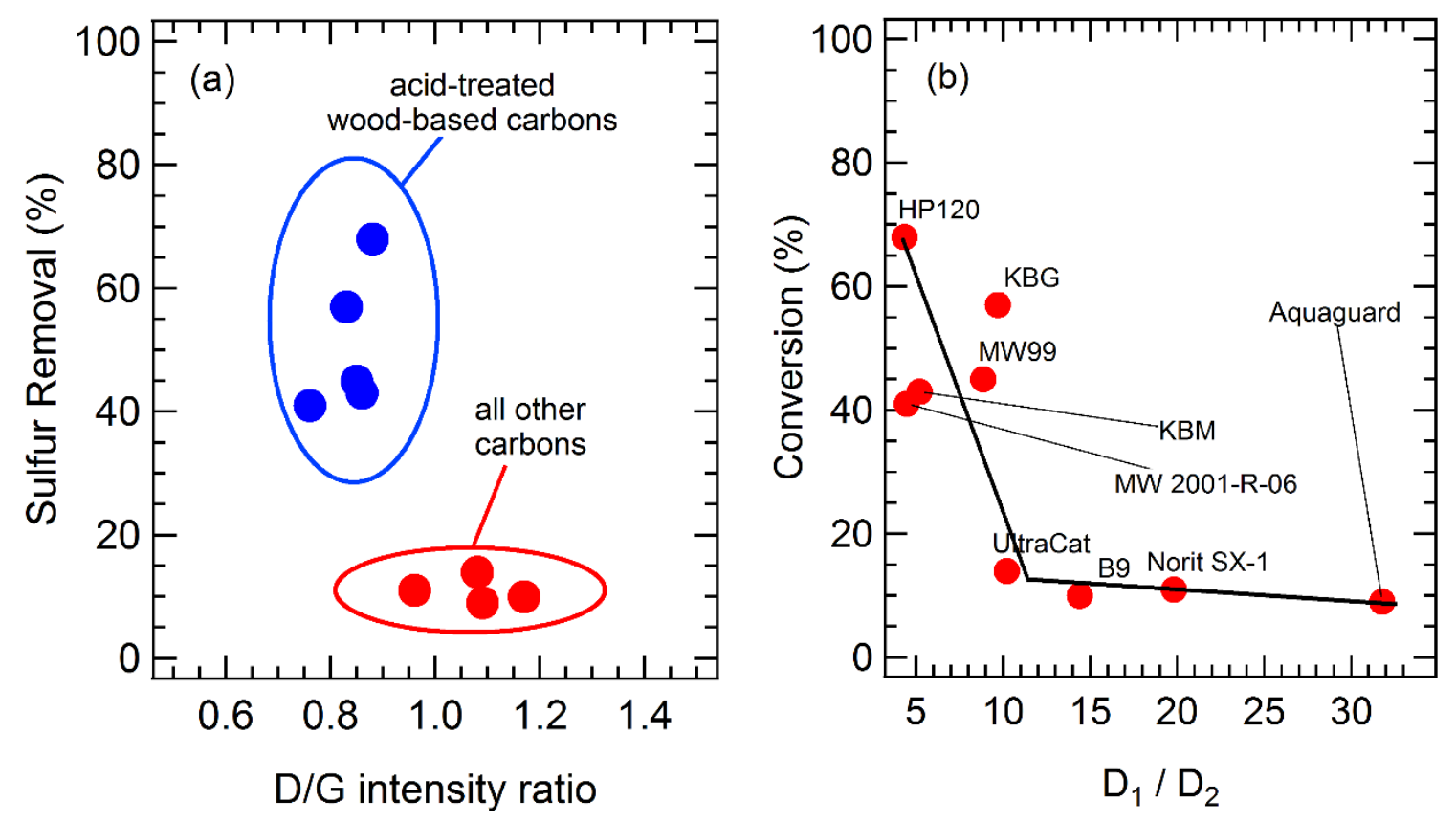

Figure 4. Raman analysis of the activated carbons: (a) $D / G$ intensity analysis and (b) $D_{1} / D_{2}$ analysis (ratio of edge to basal plane defects).[77] 


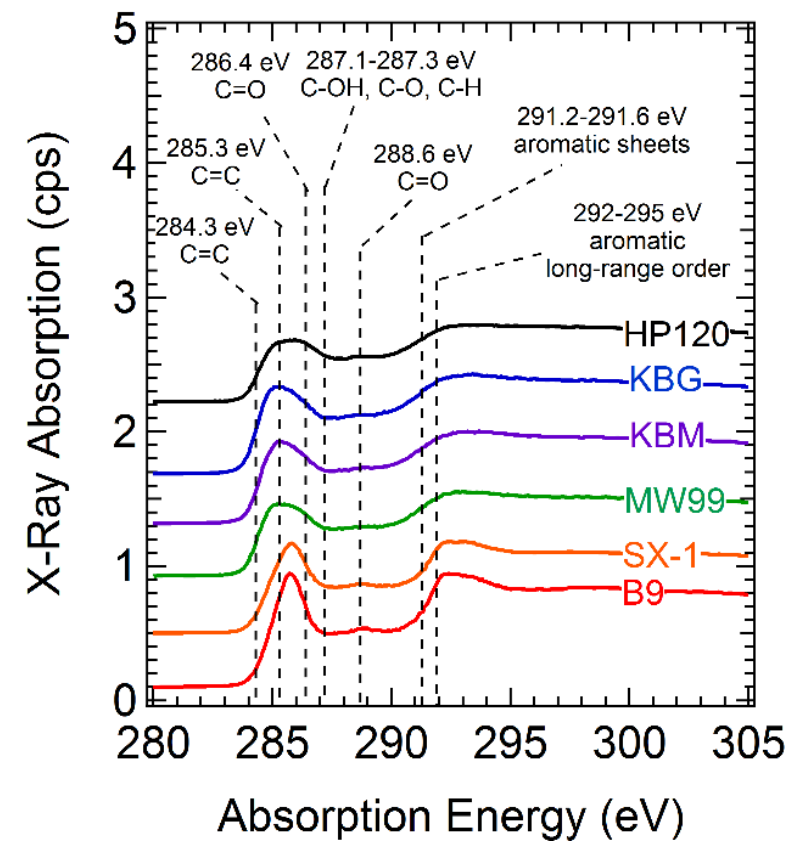

Figure 5. C K-NEXAFS spectra of carbon materials 


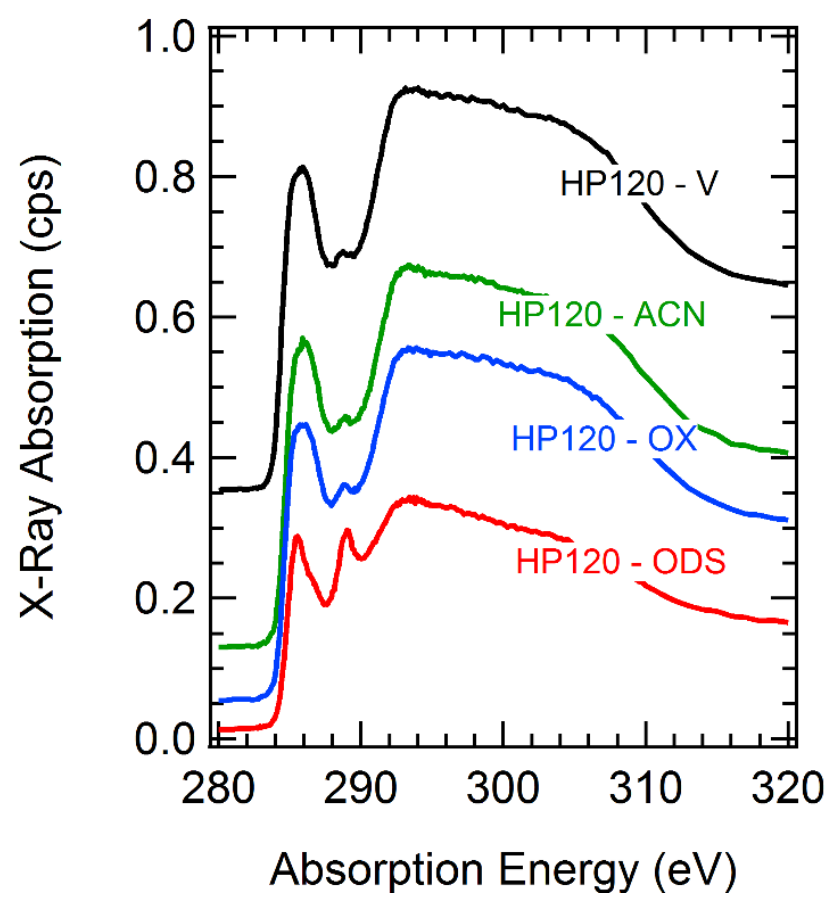

Figure 6. Carbon K-NEXAFS spectra of HP 120 before and after various treatments: HP120-V is virgin HP 120 with no treatments; HP120-ACN is acetonitrile rinsed HP 120; HP120-OX is HP 120 exposed to the oxidant; HP120-ODS is HP-120 after ODS treatment of whole JP-8. 